Article

\title{
Investigate the Conduction Path of Stakeholder Conflict of Urban Regeneration Sustainability in China: the Application of Social-Based Solutions
}

\author{
Yiming Wang ${ }^{1, *}$ and Pengcheng Xiang ${ }^{1,2, *}$ \\ 1 School of Management Science and Real Estate, Chongqing University, Chongqing 400044, China \\ 2 International Research Center for Sustainable Built Environment, Chongqing University, \\ Chongqing 400044, China \\ * Correspondence: yimingwang@cqu.edu.cn (Y.W.); pcxiang@cqu.edu.cn (P.X.)
}

Received: 22 August 2019; Accepted: 24 September 2019; Published: 25 September 2019

\begin{abstract}
Urban regeneration, as an important way to enhance urban sustainable development capacity, is advancing at a high speed in China. However, urban regeneration involves various stakeholders, and there are frequent conflicts between these stakeholders due to the vast differences in their interests. When conflicts among stakeholders are not effectively controlled, they can have serious negative social and economic impacts, such as increased pressure on the government to maintain stability, increased costs to developers and reduced willingness of property owners to participate. These are all critical factor affecting the sustainability of urban regeneration. Therefore, this paper explored the mechanism underlying stakeholder conflict conduction in urban regeneration. Next, a literature review and case study were conducted to identify key conflict factors. Then, the factors of stakeholder conflict were assessed using questionnaire survey. Finally, the structural equation model (SEM) was used to analyze the pathways of stakeholder conflict conduction in urban regeneration; and 35 conflict conduction paths were found. Based on Pareto's Law, 7 of the 35 stakeholder conflict paths were identified as critical paths with coefficients between $0.245-0.364$. Empirical results revealed that different types of conflict factors have different impacts on stakeholder conflict conduction, among which interest distribution and stakeholder coordination were the critical factors to be considered. The findings provide alternatives Social-Based Solutions (SBS) for resolving stakeholder conflicts and provide practical guidance for integrating stakeholders, which is important to ensuring the sustainability of urban regeneration.
\end{abstract}

Keywords: urban regeneration; sustainability; stakeholder conflict; conduction path; structural equation model; social-based solutions

\section{Introduction}

As an important way to achieve people-oriented sustainable urbanization, urban regeneration has received increasing attention from the governments and society [1]. The speed of economic development in China in the 21st century has far exceeded the expectations of the world, and the scale of expansion and speed of development of urban space and the population are also unique [2]. However, such a rapid pace of development has also intensified the pressure on the supply of land for construction and the speed of infrastructure construction in major cities in China [3]. For example, it is estimated that Shenzhen will have less than 60 square kilometers of new construction land by 2020 [4]. More importantly, the available land for construction can barely meet the construction needs of Shenzhen's major public projects in terms of scale and location [5]. At the same time, the lack of land space has also hindered the transformation of urban industry as well as social and 
economic development. In the context of constraints such as incremental land use and the resource environment, in order to cope with sustainable development, major cities have to turn their attention to the construction of stock land. As important locations of urban stock land, old residential areas, urban villages and shanty towns have become the key focus of governments in the regeneration of stock land areas [6]. The regeneration of old urban areas, including old residential areas, urban villages and shantytowns, can not only allow for the redevelopment of urban land that is currently being inefficiently used, but can also contribute to construction of regional infrastructure and supporting facilities, and thus, improve the quality of life of the residents [6]. First-tier cities such as Beijing, Shanghai, Guangzhou and Shenzhen have formulated large-scale regeneration plans for old urban areas. For example, in the 13th Five-Year Plan for Shanghai Housing Development, it is stated that by 2020 , the scale of regeneration of old residential areas will reach 300,000 households and the regeneration area will reach 50 million $\mathrm{m}^{2}$ [7]. At present, the regeneration of these old urban areas is gradually spreading to the central and western regions, and corresponding urban regeneration planning is also occurring in new front-line cities such as Chongqing, Chengdu, $\mathrm{Xi}^{\prime}$ an and Wuhan. For example, in 2019-2020, Chongqing is expected to regenerate nearly 120,000 shantytowns, with a planned investment of about 62 billion Yuan [8].

While urban regeneration plays a very important role in the construction of new urban areas, governments and societies must formulate corresponding implementation plans to ensure the smooth regeneration of these areas. However, currently, the proportion of urban regeneration projects that have been smoothly implemented has not met expectations [9]. According to data from Guangzhou and Shenzhen, which are areas that are relatively mature in terms of urban regeneration work in China, less than $30 \%$ of regeneration projects have been successfully implemented [4]. Many of these projects were approved for regeneration as early as 2009 , but were not officially launched until the end of 2018 [4]. Thus, it is clear that the implementation of urban regeneration projects is very difficult. The main reason for this is that the regeneration process involves many stakeholders, such as the government, owners and developers. The relationship between these stakeholders is complex and coordination is very difficult. Urban regeneration involves many factors, including project planning, land expropriation, housing demolition and resettlement of owners; these factors are closely related to the various stakeholders [10]. Moreover, with the creation of a democratic society and the enhancement of owners' awareness of rights, owners and the public also have a strong will to participate in the urban regeneration planning process, and no longer passively accept the arrangements of other strong stakeholders; this further increases the complexity and difficulty of urban regeneration project implementation. With increased regeneration of old urban areas in land stock areas, the scale of housing expropriation is gradually expanding, and social contradictions caused by land expropriation and housing demolition do occur. The Blue Book of Society 2019 analysed the causes of various mass incidents in recent years and reported that the mass incidents caused by land expropriation and demolition accounted for more than $50 \%$ of the total number of incidents [11]. This finding is supported by evidence of many conflicts in urban regeneration projects over the past ten years, including self-immolations [12], violent demolitions [10], banner protests [4] and nail households [13]. The Yangjiaping demolition incident in Chongqing, the Yihuang self-immolation incident in Jiangxi and the Hongshan village regeneration incident in Wuhan have had many extremely negative effects on the respective cities because of the fierce conflict among the various stakeholders involved. If effective measures are not taken to mitigate such stakeholder conflicts in urban regeneration, escalation of mass incidents will occur including violent demolitions, large-scale petitions and protest demonstrations. These incidents could have a significant social impact. For example, such incidents are often disseminated by news media, resulting in further negative social effects. The noise may be more serious. Such incidents ultimately have a serious negative impact on new urbanization and the sustainable development of the social economy in China, and may even endanger the stability of the whole society. 
The key to mitigating these problems is to clarify the complex relationships and sources of conflicts involved in urban regeneration. Domestic and foreign scholars have discussed the causes of, and factors influencing, conflicts among various stakeholders in urban regeneration. Some scholars report that the inadequacy of laws and regulations is the main reason why the conflicts among various stakeholders occur in urban regeneration. Xi (2018) examined the issue from the perspective of the legal system and suggested that, in terms of demolition and relocation, there is no departmental law that is consistent, rigorous and mutually responsive [14]. Agbiboa (2017) studied urban regeneration projects in Lagos, and found that the major cause of the large-scale conflict was that Nigeria had not yet established perfect laws and regulations, and there were insufficient social security measures for the owners who have lost their housing and land [15]. Unclear property rights are also considered to be an important cause of stakeholder conflicts in urban regeneration. Yang and $\mathrm{Xu}$ (2016) reported that the contradictions and conflicts between various stakeholders that occured during urban regeneration were directly related to the conflicts between personal interests, collective interests and social interests; specifically, conflicts between the personal interests of the demolished and the commercial interests of the developing enterprizes [16]. Peng (2018) purported that the institutional reason for conflict between stakeholders was that the identification of "public interest" was not accurate enough, and was not clearly distinguished from personal interests [17]. At the same time, the rationality of interest compensation is also considered to be one of the most important reasons for conflicts among stakeholders in urban regeneration. Lees (2014) studied social conflicts in urban regeneration in London and found that conflicts were mainly caused by the distribution of economic interests among developers and residents [18]. Wang et al. (2017) examined the causes of conflicts among core stakeholders in various urban regeneration projects and found that although there are many categories and modes of urban regeneration projects, the causes of conflicts primarily revolve around the distribution of economic interests [19]. In addition, inaccurate government positioning is also considered by some scholars to be an important factor affecting stakeholder conflicts. Yu et al. (2019) found that the compliance of government departments to decision-making procedures played an important role in stakeholder conflicts in urban regeneration [20]. Ruming (2017) conducted a study from the perspective of stakeholders and examined the key factors in the success of urban brown land renewal. It was found that government supervision was the most critical factor [21]. Several scholars have also identified other factors that cause stakeholder conflicts, including poor communication of information [22], an inadequate conflict management system [23], insufficient channels for public participation [24], immature project management [25], insufficient capacity of developers [9] and differences in resource mastery [12].

Although the research on the causes of conflicts is relatively mature, most studies have used qualitative methods or case studies to analyze and study the factors influencing stakeholder conflicts, with the majority of studies based on theoretical analysis and empirical summarization. In addition, many studies of stakeholder conflict have focused on individual factors or individual analysis of several factors; thus, there is a lack of in-depth analysis of the impact of multiple factors and there are no theoretical models that have strong explanatory power for stakeholder conflicts. More importantly, research on the generation, evolution and conduction of stakeholder conflicts in urban regeneration is relatively scattered and inadequate. Few scholars have carried out basic exploration of stakeholder conflict conduction in urban regeneration. Wang (2017) proposed that a comprehensive analysis of stakeholder conflict conduction pathways is an important basis for promoting the sustainability of urban regeneration [19]. The relationship and paths between stakeholder conflict elements must be appropriately quantified [22]. Exploring the sources of stakeholder conflict, the paths of conflict conduction, the results of conflict conduction and the critical factors involved in conflict conduction are key to solving the problem of stakeholder conflict in urban regeneration. To this end, it is necessary to thoroughly analyse the conduction paths involved in stakeholder conflict in urban regeneration in China in order to promote the sustainability of urban economies and society. 
The remaining sections of this paper are summarized as follows. After introducing the background and describing the existing literature to this paper in Section 1, an analysis of stakeholder conflict conduction mechanisms in urban regeneration is presented in Section 2. The methods used to investigate the conduction paths of stakeholder conflict are described in Section 3. The results are described in Section 4, as well as discussed in detail in this section. Finally, conclusions and policy implications of this paper are outlined in Section 5.

\section{Analysis of Stakeholder Conflict Conduction Mechanism in Urban Regeneration}

Urban regeneration involves many stakeholders, each stakeholder's interests are different and this leads to stakeholder conflicts [11]. To resolve the conflicts, it is necessary to know which major stakeholders exist in urban regeneration implementation, what conflicting factors exist among the major stakeholders, how these conflict factors are conducted, and what are the root causes of these conflict factors.

\subsection{Conflict Analysis of Core Stakeholders}

According to stakeholder theory and Mitchell's scoring method [18], the core stakeholders include governments, developers and owners; these core stakeholders are most strongly and directly correlated with the implementation of urban regeneration [23]. It is necessary to understand the forms and characteristics of conflicts among these core stakeholders. Government, developers and property owners have opposing interests in urban regeneration. Governments hope to expand land reserve sources [3], obtain more land transfer income [6] and solve the problems remaining after land expropriation [3]. On the other hand, developers expect to maximize their profit from project development [17], while owners hope to obtain higher compensation for demolition and relocation [18]. These different interest demands constitute a reciprocal benefit circle; each stakeholder's game changes will affect the vital interests of other parties (Figure 1). The forms and characteristics of conflicts among the three core stakeholders can be summarized as follows:

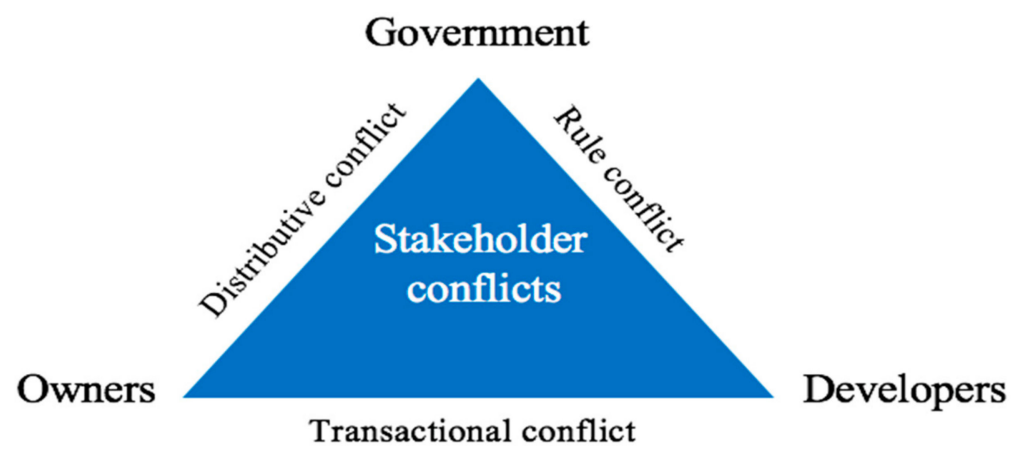

Figure 1. The Conflict among stakeholders in the urban regeneration process.

(1) Conflicts between the government and owners focus on the distribution of interests [4]. It is difficult to reach an agreement on the distribution of value-added benefits in urban regeneration. The government considers the distribution of value-added benefits from the perspective of social development as a whole, while the owners want to obtain as much compensation as possible based on their personal interests;

(2) Conflicts between developers and owners focus on the transaction of property rights [12]. Developers and owners can negotiate the regeneration terms according to the market rules. However, case studies have revealed that, due to the great variation in the degree of resources available, it is difficult for property owners, as a disadvantaged party, to trade property rights equally with developers;

(3) Conflicts between the government and developers focus on the implementation rules [15]. Rules concerning development include volume ratios and the construction of supporting facilities. On the one hand, the government guides and controls the behavior of developers by formulating 
relevant development rules. On the other hand, in order to maximize their interests, developers constantly try to change and break the development rules formulated by the government, for example, by increasing the volume ratio and changing the proportion of land designated as commercial and residential.

Based on the above, it is evident that diverse stakeholder interests lead to complex stakeholder conflicts. Therefore, it is necessary to systematically analyse the causes, events and consequences of conflicts, and to explore the paths of conflicts in the urban regeneration process.

\subsection{Analysis of Conflict Conduction Mechanism of Stakeholders}

Conflict refers to the potential for an activity or accident to occur in a particular environment during a certain period of time; it reflects the degree of difference between the desired result and the actual result [22]. It can also be interpreted as the uncertainty of the occurrence of conflict events and the loss of uncertainty due to the influence of certain factors. It is known that conflicts are not isolated and static but are in interrelated and constantly moving. The conduction of conflict is a gradual process involving qualitative change caused by quantitative changes; the conduction of conflict follows certain rules and mechanisms [17]. The domino theory [26] and the energy transfer theory [13] theoretically elaborate on the mechanisms underlying conflict conduction. According to the domino theory, the conflict conduction process is a chain reaction that can be expressed graphically by a causal chain linked end to end [26]. According to the theory of energy transfer, the conduction of conflict is essentially energy transfer as a result of conflict energy exceeding the range that the system can bear [13]. The above two theories indicate that the conflict is not formed instantaneously; rather energy accumulates over a long period of time and breaks out when the system exceeds its limit; the energy then passes to the next link and so on. Energy continues to accumulate and once again exceeds the threshold, causing the eruption of the sequential chain conduction process. Usually, this process is decomposed into three parts: conflict sources (factors), conflict events and conflict outcomes [13]. Conflict sources lead to conflict events, and conflict events further lead to conflict outcomes. In urban regeneration, due to the various uncertain factors in the internal and external environment, energy accumulates within the system, continuously exceeds the range of system tolerance, and is conducted from conflict factors to conflict events, and finally from conflict events to conflicts. As a result, the loss occurs, which is the general mechanism of conflict conduction. There are various objective, uncertain factors involved in the urban regeneration process, including economic, social, ecological environment and management factors.

When the interests of the core stakeholders cannot be met, conflict factors can emerge. These conflict factors will become the drivers of individual events and will begin to pose potential hazards to the urban regeneration process and even to related socio-economic systems [6]. At the same time, these dynamic conflict chains depend on several conduction carriers, such as information and media [12]. As these individual conflicts occur, they attract the attention of other owners and the public, and with the rapid coverage of social media, an increasing number of stakeholders become involved in the mass incident. The occurrence of individual conflicts accelerates the conduction of stakeholder conflicts in urban regeneration. Owners who have lost interests will initially pursue legal channels to ensure their interests; such channels includ appeals to petitions and administrative litigation. When these legal problems are not solved, the owners will inevitably adopt irrational channels, such as hanging banners, illegal gatherings and demonstrations [15]. In addition, media reports and mass communication will further increase the dissatisfaction of property rights groups, which may eventually lead to mass incidents; mass incidents affect the sustainable operation of the social economy. The specific conduction process is shown in Figure 2. 


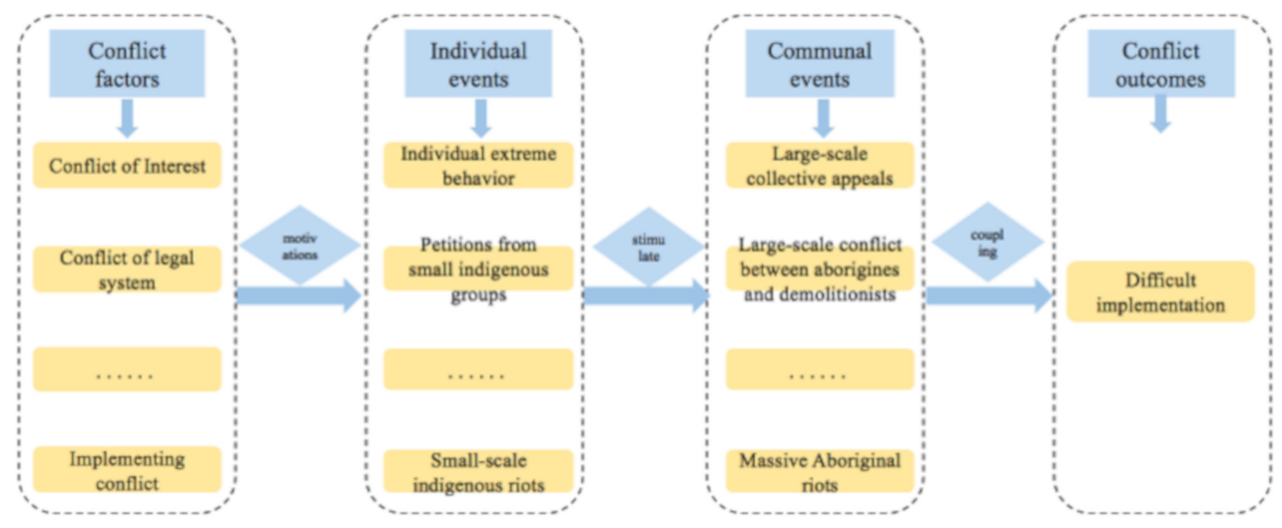

Figure 2. Conflict conduction.

\section{Materials and Methods}

Conflict factors relevant to urban regeneration were identified systematically through a literature review and case studies. This paper analyzes those conflict factors by structural equation model (SEM). The research steps and methods, as well as the research objectives, are shown in Figure 3.

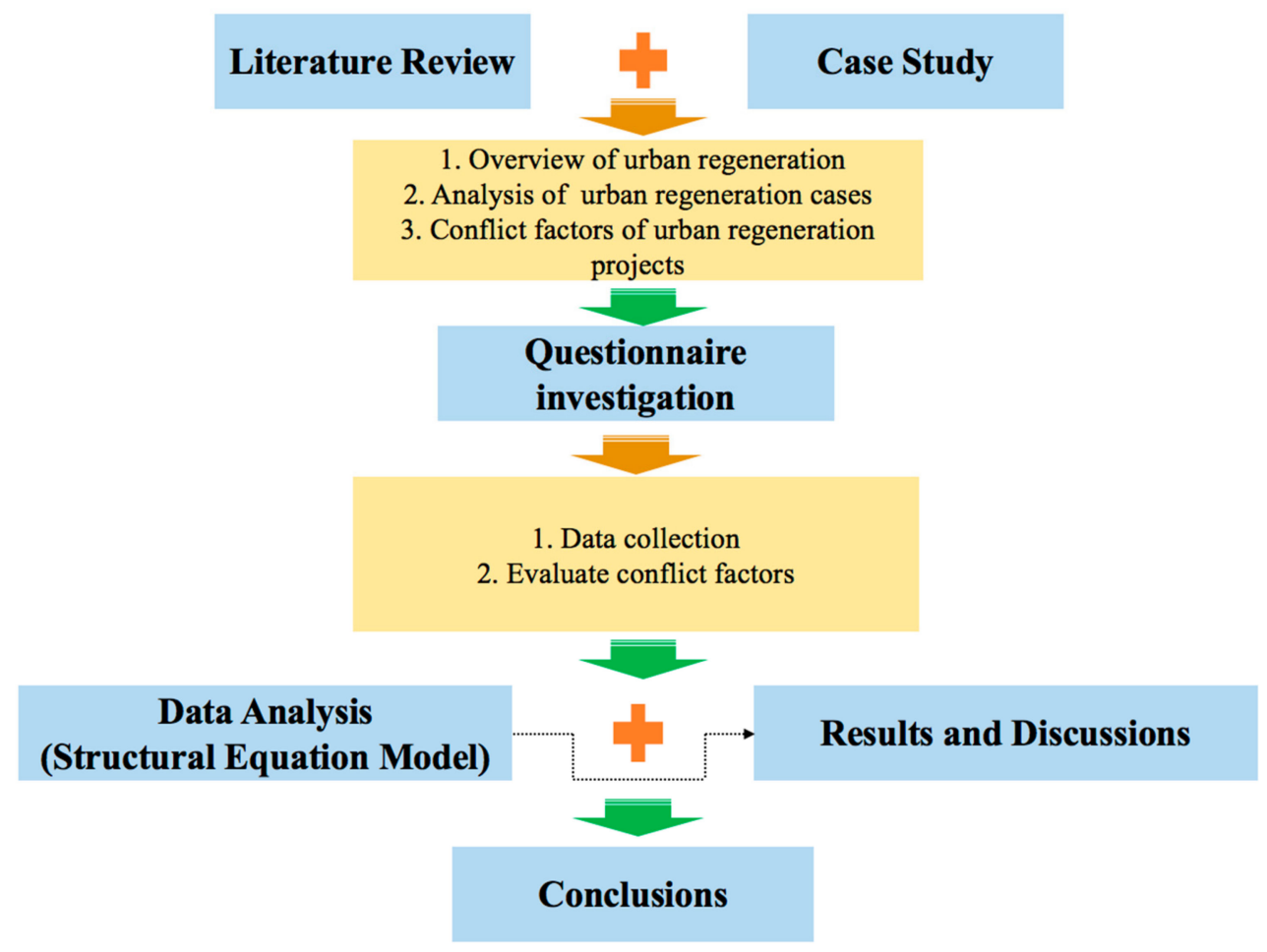

Figure 3. Research procedure and frame of this paper.

\subsection{Identification of Stakeholder Conflicte Elements in Urban Regeneration}

Although there is substantial foreign research on stakeholder conflict, given that theory, practice and the economic, social and cultural conditions of stakeholder conflicts in urban regeneration are inseparable, the current research may not accurately reflect the practice of urban regeneration in China. Further, the timeliness of published research is relevant given the rapid development in urban regeneration trends. Therefore, this paper will focus on the analysis and interpretation of research literature on stakeholder conflict in urban regeneration in China published between 2009 and 2018. A literature search was performed on the CNKI and Web of Science platforms in order to extract the key elements of stakeholder conflict. The literature searches of the CNKI and Web of Science 
databases revealed that more than 550 relevant studies have been published in the past ten years. Through preliminary analysis, 261 valid journals articles were obtained. Then, we performed manual examination and analysis of articles including title, author, source of literature, keywords, publication time, document classification number and number of citations. Following this, 19 articles were used as core documents to identify stakeholder conflicts in urban regeneration, including papers by Liu and Zhang (2015), Xu et al. (2019), Liu et al. (2019), Tan and Altrock (2016), Xi (2018), Peng (2018), Guo et al. (2017), Wang et al. (2017), Yu et al. (2019), Lian et al. (2017), Tao and Qi (2018), Liu et al. (2018), Tao (2015), Wang and Shen (2015), Sun and Zhou (2015), Xie and Zhou (2014), Lai and Tang (2016), Shao (2015), Tang (2016).

In addition, we found some differences between academic understanding and practical understanding of urban regeneration. Therefore, in order to make up for the shortcomings of the conflict factors identified in the literature search, several representative cases of urban regeneration projects were collected and analyzed. This allowed us to fully evaluate conflict factors. The cases were identified as follows. The research team collated and summarized almost all kinds of urban regeneration projects, including field research data, books, images and literature; these projects were identified through domestic professional urban regeneration project research sites (e.g., Urban and Small Town Reform and Development Center of China, Urban regeneration WeChat Official Accounts), official information from central and local governments (e.g., Development Research Centre of the State Council, the Ministry of Housing and Construction) and from news sites. With the help of staff engaged in urban regeneration, we selected 10 typical urban regeneration projects including the Shenzhen Mutoulong regeneration project, Chongqing Shibati regeneration project, Guangzhou Wenchong village regeneration project, Chongqing Huangjueping regeneration project, Yangzhou Dujiangqiao regeneration project, Pingdingshan machinery plant residential district regeneration project, Shanghai Qingpu regeneration project, Wuhan Hongshan village regeneration project, Chengdu Chenghua district regeneration project and Jiangxi Yihuang Hedong district regeneration project. These typical cases were demonstrative projects in various fields and are projects that have attracted widespread attention. Through the analysis of the various cases, we identified 33 conflict factors, 15 conflict events and 4 conflict outcomes.

As discussed in Section 2, conflict refers to the potential possibility of occurrence of activities or accidents and the difference between the result of intentions and the reality during a given period of time. It can also be interpreted as the uncertainty of conflict events and the loss of uncertainty caused by some factors. Figure 2 illustrates the law of conflict conduction. Various conflict factors first trigger individual events and stimulated by certain situations, individual events further upgrade to group events; ultimately, under the coupling of internal and external situations, group events trigger conflict outcomes such as the failure of urban regeneration. Based on the existing research, this paper divides conflict factors into five indicators: interest, legal, social, implementation and management. Each indicator includes several subdivisions, for example, interest factors include owners' loss of housing, unreasonable compensation standards, etc. In addition, according to the law of conflict conduction in Figure 2, the conflict events can be further divided into individual events and communal events based on the relationship between the occurrence time and the conduction effect. Individual events as the mediator of conflict conduction underly the occurrence of communal events. In summary, as shown in Table 1, including conflict factors, conflict conduction mediators (individual events), conflict events (communal events) and conflict outcomes, we have a list of stakeholder conflicts in urban regeneration.

\subsection{Questionnaire Design}

Based on the identified conflict factors, a pilot questionnaire "Conflict factors of urban regeneration projects in China" was designed. In order to obtain a clearer and more reliable result, the pilot questionnaire was sent to the invited person and each participant independently completed it. Respondents reported that the list covered the conflict factors involved in various urban regeneration 
projects. The questionnaire consisted of two parts, the first part collected basic information on the participant while the second part listed the conflict factors and required respondents to answer according to their own practical experience. Responses were scored on a 5-point Likert scale assessing the importance of each factor. The degree of importance was rated in 1 to 5 , with $1=$ extremely unimportant, 2 = unimportant, $3=$ normal, $4=$ important, $5=$ extremely important.

Table 1. The Inventory of Conflict Conduction Composition of Stakeholders in Urban Regeneration.

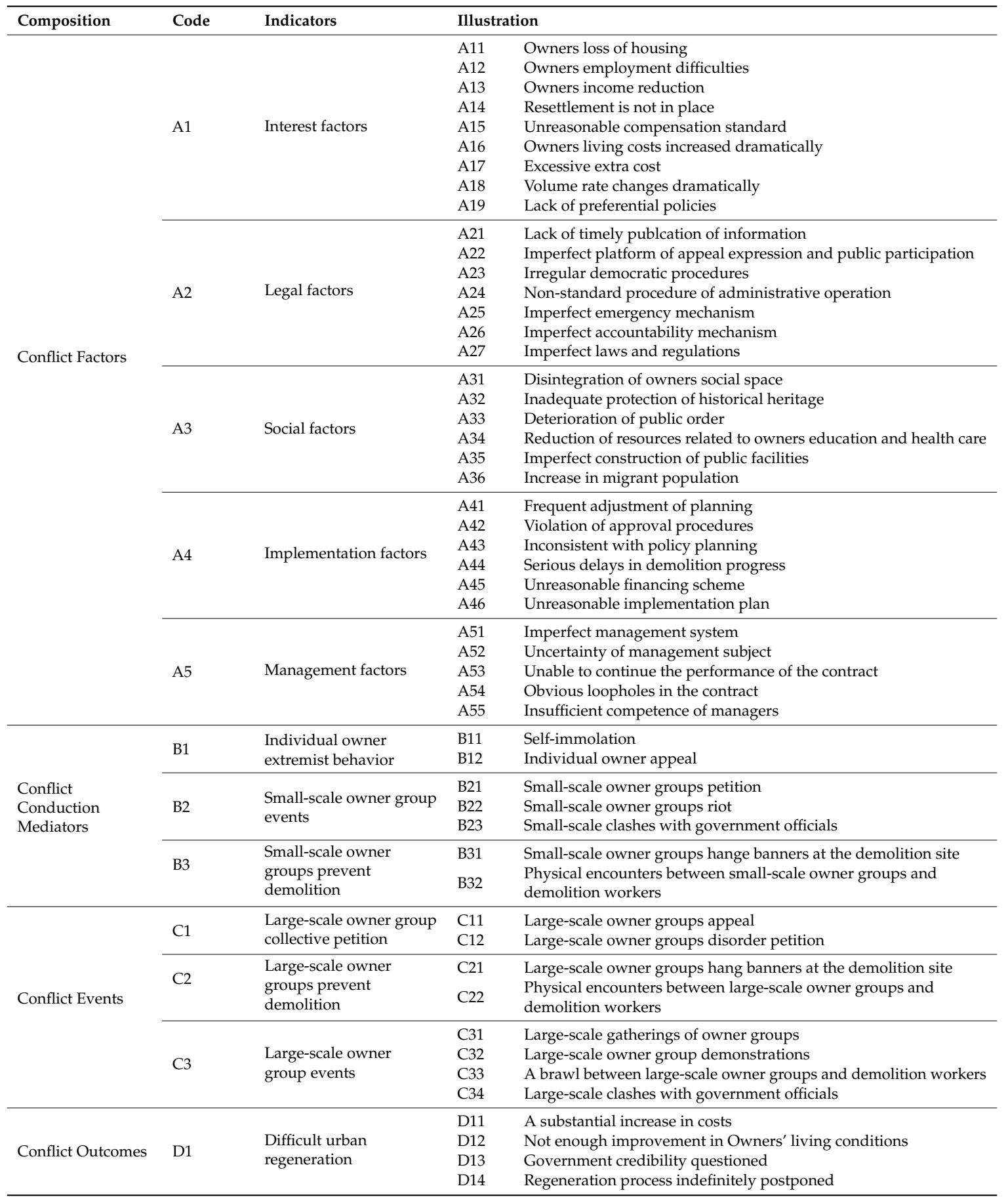

\subsection{Data Collection}

After further optimization and improvement of the questionnaire, the research team published the questionnaire through the website (www.wenjuan.com). The potential sample was divided into 
three groups: government officials, developers and investors, relocated householders. Following the distribution of the questionnaire, all respondents were contacted to ensure that they received the questionnaire and that they agreed to participate in the study. A questionnaire such as this is the most cost-effective way to survey large samples of participants.

The study team distributed 400 questionnaires to the three groups of respondents; a total of 205 questionnaires were returned. Of these, 8 respondents reported that all factors were 'extremely important'. Thus, it was determined that these questionnaires were unreasonable and were therefore removed. In addition, 14 questionnaires had a large degree of missing data and thus, were excluded. The remaining 183 questionnaires were deemed valid by the research team. Therefore, the overall effective response rate for the questionnaire was $45.73 \%$. The effective response rates for each group of participants are shown in Table 2.

Table 2. Response rate of questionnaire survey.

\begin{tabular}{lllll}
\hline & $\begin{array}{l}\text { Government } \\
\text { Officials }\end{array}$ & $\begin{array}{l}\text { Relocated } \\
\text { Householders }\end{array}$ & $\begin{array}{l}\text { Developers } \\
\text { and Investors }\end{array}$ & Total \\
\hline Number of questionnaires sent out & 150 & 150 & 100 & 400 \\
Number of completed questionnaires received & 72 & 75 & 36 & 183 \\
Response rate & $48.00 \%$ & $50.00 \%$ & $36.00 \%$ & $45.75 \%$ \\
Percentage in the sample & $39.34 \%$ & $40.98 \%$ & $19.76 \%$ & $100 \%$ \\
\hline
\end{tabular}

\subsection{Data Analysis}

As a multivariate linear statistical modeling technique, SEM is widely used in various fields, especially in sociology and management [27]. Traditional statistical methods cannot cope with increasingly complex and variable linear relationships and cannot deal with latent variables that cannot be directly measured. SEM can overcome these issues. SEM includes two types of basic models: a measurement model and a structural model. The measurement model describes the relationship between latent variables and observed variables, and the structural model describes the relationship between latent variables [27].

\subsubsection{Measurement Model}

The measurement model consists of latent variables and observed variables. In mathematical terms, a measurement model is a linear function of a set of observed variables. Usually, the relational equation to express the relationship between them is as follows.

$$
\begin{aligned}
& \mathrm{X}=A_{x} \xi+\delta \\
& \mathrm{Y}=A_{y} \eta+\varepsilon
\end{aligned}
$$

where $\xi$ represents the external latent variable (dependent variable), $\eta$ is the intrinsic latent variable (fruit variable), and $\mathrm{X}$ represents the vector consisting of external factors and $\mathrm{Y}$ represents the vector consisting of internal factors. $A_{x}$ represents the matrix of correlation coefficients between $\mathrm{X}$ and external dependent latent variables, $A_{y}$ represents the matrix of correlation coefficients between $\mathrm{Y}$ and the intrinsic latent variable. $\delta$ represents the measurement error of the $X$ variable and $\varepsilon$ is the measurement error of the $\mathrm{Y}$ variable

\subsubsection{Structural Model}

The structural model shows the relationship between potential variables and can be expressed as follows:

$$
\eta=\mathrm{B \eta}+\Gamma \xi+\zeta
$$


where $\xi$ represents the external latent variable (dependent variable), $\eta$ is the intrinsic latent variable (fruit variable), and $B$ is the coefficient matrix of endogenous latent variables, $\Gamma$ is the coefficient matrix between the external latent variable and the internal latent variables and $\zeta$ is the random interference term.

Conflict is an abstract concept composed of several specific conflict factors. Thus, the relationship between conflict conduction compositions and corresponding indicators is very similar to the relationship between latent variables and observed variables in the SEM. As such, in this study, conflict was regarded as a latent variable and conflict factors were regarded as the observed variables. Measurement of observed variables can be directly obtained through questionnaires or literature studies, while latent variables must be obtained by observing variables to form an observation model. The measurement model shows the relationship between latent variables and observed variables. The literature analysis, case studies and logical reasoning presented above identified 33 stakeholder conflict factors in urban regeneration. These 33 factors were divided into 5 indicators: interest factors, legal factors, social factors, implementation factors, and management factors. Further, there were 7 factors underlying conflict conduction mediators, 8 factors underlying conflict events, and 1 factor underlying conflict outcomes.

Based on the stakeholder conflict list in the urban regeneration process presented in Section 2.2 and the theoretical model of stakeholder conflict conduction in the urban regeneration process presented in Section 3.2, a structural equation model was constructed. After model correction, a structural equation model of stakeholder conflict conduction in the urban regeneration process was obtained (as shown in Figure 4). The path coefficients marked on the lines in Figure 4 reflect the strength of the correlation between the various conductive elements.

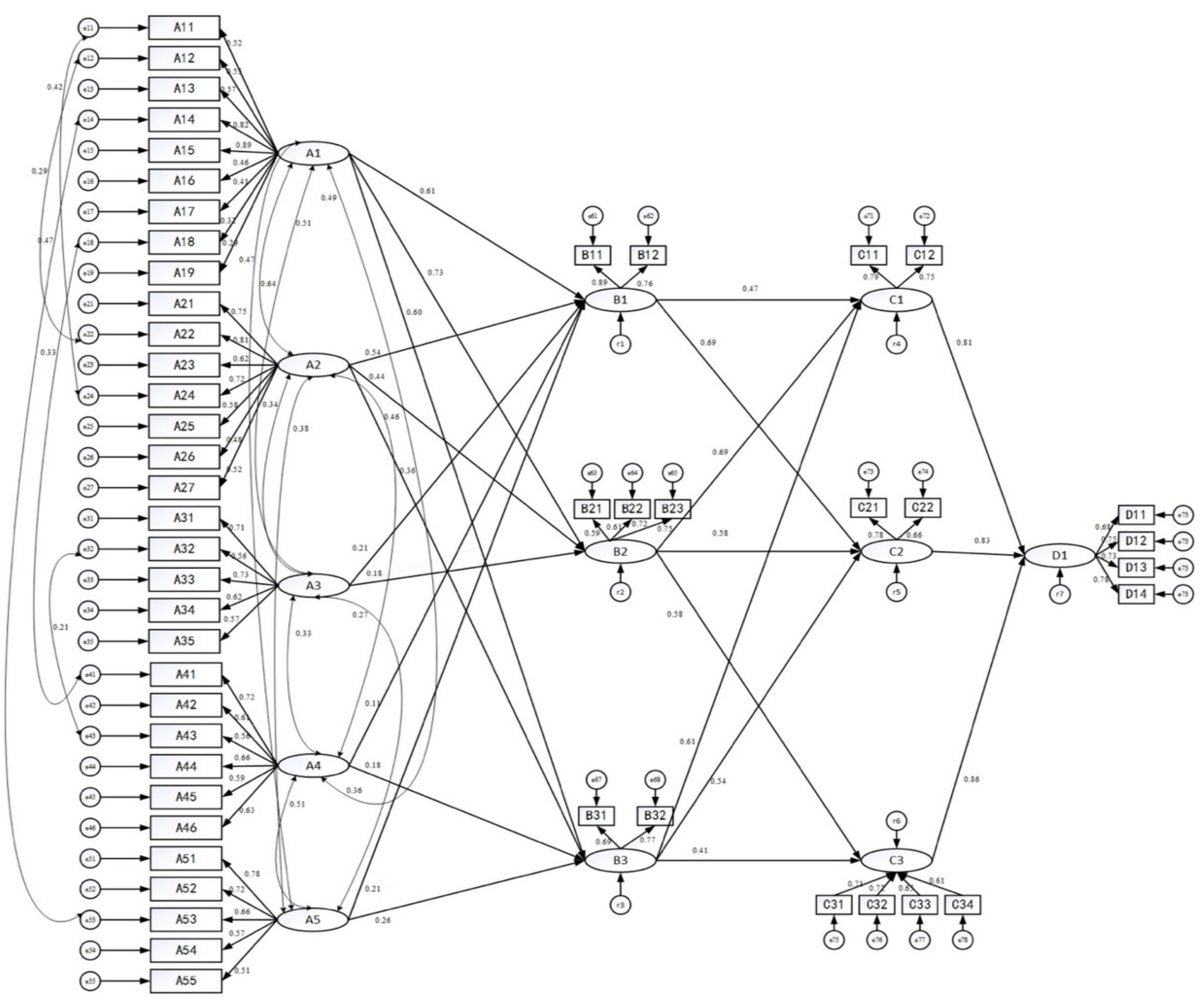

Figure 4. Standardized path diagram. 


\section{Results and Discussion}

\subsection{Identification of Stakeholder Conflict Conduction Paths in Urban Regeneration}

The revized model (as shown in Figure 4) reliably and realistically reflects the conduction process of stakeholder conflicts in the urban regeneration process. The unreasonable path in the theoretical model was deleted, and the final model of the stakeholder conflict conduction path in the urban regeneration process is shown in Table 3.

Table 3. Stakeholder Conflict Paths.

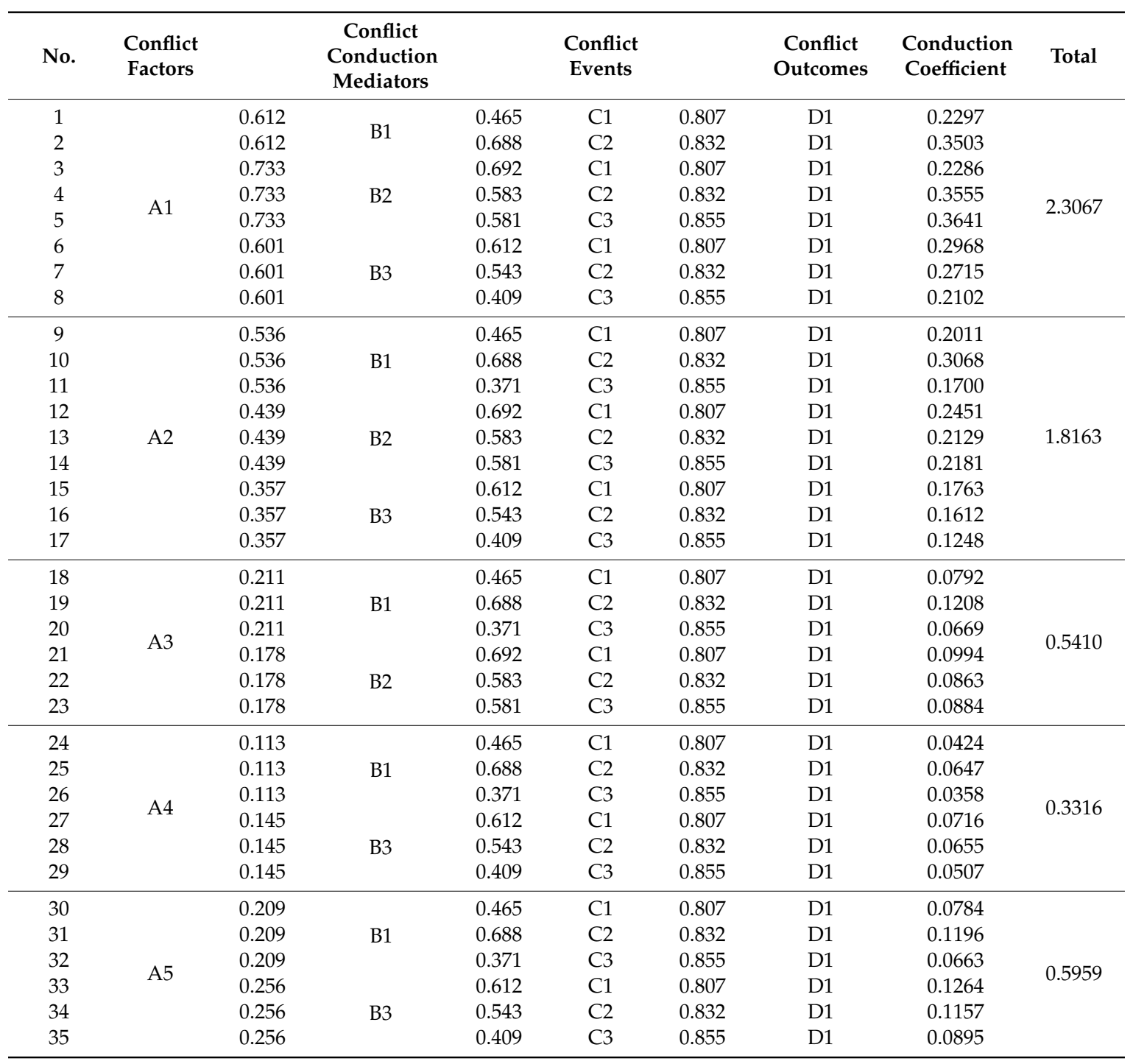

Due to the large number of stakeholder conflict conduction paths in the urban regeneration process, it is difficult in practice to address all potential pathways of conflict. According to Pareto's Law, in a system, $80 \%$ of the factors will account for only $20 \%$ of the effect on the whole system, while the remaining $20 \%$ will contribute to $80 \%$ of the effect [28]. This $20 \%$ factor is called the "key minority". Therefore, the key to the stakeholder conflict path analysis in urban regeneration is to identify the "key minority" in the 35 conduction paths, and to focus on these pathways so as to propose conflict resolution measures based on theoretical and empirical findings. According to the "28 Principles", the conflict conduction paths in Table 4 were arranged in order from the largest to the smallest. The top $20 \%$ of pathways were selected as the focus, and the 7 critical conflict conduction ofstakeholders in urban regeneration was obtained. The paths are shown in Table 4. 
Table 4. Critical Path of Conflict Conduction.

\begin{tabular}{|c|c|c|c|c|c|c|c|c|}
\hline No. & $\begin{array}{l}\text { Conflict } \\
\text { Factors }\end{array}$ & & $\begin{array}{l}\text { Conflict } \\
\text { Conduction Mediators }\end{array}$ & & $\begin{array}{l}\text { Conflict } \\
\text { Events }\end{array}$ & & $\begin{array}{l}\text { Conflict } \\
\text { Outcomes }\end{array}$ & $\begin{array}{l}\text { Conduction } \\
\text { Coefficient }\end{array}$ \\
\hline 5 & A1 & 0.733 & B2 & 0.581 & $\mathrm{C} 3$ & 0.855 & D1 & 0.3641 \\
\hline 4 & A1 & 0.733 & B2 & 0.583 & $\mathrm{C} 2$ & 0.832 & D1 & 0.3555 \\
\hline 2 & A1 & 0.612 & B1 & 0.688 & $\mathrm{C} 2$ & 0.832 & D1 & 0.3503 \\
\hline 10 & $\mathrm{~A} 2$ & 0.536 & B1 & 0.688 & $\mathrm{C} 2$ & 0.831 & D1 & 0.3068 \\
\hline 6 & A1 & 0.601 & B3 & 0.612 & $\mathrm{C} 1$ & 0.807 & D1 & 0.2968 \\
\hline 7 & A1 & 0.733 & B3 & 0.581 & $\mathrm{C} 2$ & 0.855 & D1 & 0.2715 \\
\hline 12 & $\mathrm{~A} 2$ & 0.439 & B2 & 0.583 & $\mathrm{C} 2$ & 0.832 & D1 & 0.2451 \\
\hline
\end{tabular}

The total conduction coefficient of these 7 key conduction paths was 2.1901 , accounting for $39.168 \%$ of the total variance in stakeholder conflict conduction in the urban regeneration process. That is, nearly $40 \%$ of the conflict consequences of stakeholder conflicts in urban regeneration were caused by the 7 conduction paths.

\subsection{Analysis of Key Factors Involved in Stakeholder Conflict Conduction in Urban Regeneration}

Based on the results of Section 4.1, we focused on the above conduction paths and explored measures to resolve the conflicts among the stakeholders in urban regeneration. Next, in contrast to the stakeholder conflict list identified in Section 3.1 and the stakeholder conflict conduction path, combined with the actual situation of urban regeneration, the above 7 items were involved, as shown in Table 5.

Table 5. Seven Critical Paths.

\begin{tabular}{|c|c|c|c|c|}
\hline No. & $\begin{array}{l}\text { Conflict } \\
\text { Factors }\end{array}$ & $\begin{array}{l}\text { Conflict } \\
\text { Conduction Mediators }\end{array}$ & $\begin{array}{l}\text { Conflict } \\
\text { Events }\end{array}$ & $\begin{array}{l}\text { Conflict } \\
\text { Outcomes }\end{array}$ \\
\hline 1 & Interest factor & Small-scale owner group events & Large-scale owner group events & $\begin{array}{l}\text { Difficult urban } \\
\text { regeneration }\end{array}$ \\
\hline 2 & Interest factor & Small-scale owner group events & $\begin{array}{l}\text { Large-scale owner groups prevent } \\
\text { demolition }\end{array}$ & $\begin{array}{l}\text { Difficult urban } \\
\text { regeneration }\end{array}$ \\
\hline 3 & Interest factor & Individual owner extremist behavior & $\begin{array}{l}\text { Large-scale owner groups prevent } \\
\text { demolition }\end{array}$ & $\begin{array}{l}\text { Difficult urban } \\
\text { regeneration }\end{array}$ \\
\hline 4 & Legal factor & Individual owner extremist behavior & $\begin{array}{l}\text { Large-scale owner groups prevent } \\
\text { demolition }\end{array}$ & $\begin{array}{l}\text { Difficult urban } \\
\text { regeneration }\end{array}$ \\
\hline 5 & Interest factor & $\begin{array}{l}\text { Small-scale owner groups prevent } \\
\text { demolition }\end{array}$ & $\begin{array}{l}\text { Large-scale owner group } \\
\text { collective petition }\end{array}$ & $\begin{array}{l}\text { Difficult urban } \\
\text { regeneration }\end{array}$ \\
\hline 6 & Interest factor & $\begin{array}{l}\text { Small-scale owner groups prevent } \\
\text { demolition }\end{array}$ & Large-scale owner group events & $\begin{array}{l}\text { Difficul urban } \\
\text { regeneration }\end{array}$ \\
\hline 7 & Legal factor & Small-scale owner group events & $\begin{array}{l}\text { Large-scale owner groups prevent } \\
\text { demolition }\end{array}$ & $\begin{array}{l}\text { Difficult urban } \\
\text { regeneration }\end{array}$ \\
\hline
\end{tabular}

The mechanisms of action of the critical paths involved in stakeholder conflict conduction are described below.

(1) Interest factor $\rightarrow$ Small-scale owner group events $\rightarrow$ Large-scale owner group events $\rightarrow$ Difficult urban regeneration.

Due to the large capital investment and large number of stakeholders involved, the urban regeneration is particularly subject to conflicts of interest [9]. If compensation standards for demolition and relocation are not consistent, if resettlement is not in place, and if difficulties associated with re-employment are not resolved, stakeholder conflicts may arise. Further, conflict can result from maintenance of the vital interests of the owners [29]. As a result, relocated householders (owners) are dissatisfied with the developers and even the local government; this dissatisfaction will eventually lead to conflicts such as small-scale owner groups making troubles and holding demonstration [30]. The case studies revealed that conflicts among stakeholders will escalate to different levels until 
large-scale collective gatherings, demonstrations, violence and other mass incidents of owner groups are triggered; this makes it difficult for continued implementation of urban regeneration projects.

(2) Interest factor $\rightarrow$ Small-scale owner group events $\rightarrow$ Large-scale owner groups prevent demolition $\rightarrow$ Difficult urban regeneration.

In China, the primary land market is monopolized by the government, which is the main land supplier [16]. Compared with the government, the relocated householders (owners) affected by urban regeneration are in a disadvantaged position. When a regeneration plan is completed, the government and developers hope to force owners to accept the relevant compensation and resettlement package using their available political and financial resources so as to minimize the cost of project development [31]. In this situation, owner groups without financial and political resources may defend their own interests through small-scale collective petitions, demonstrations and other means, as a bargaining chip to be used again the government and developers [27]. If the local government fails to provide timely guidance and effective solutions, such small-scale incidents will gradually escalate, resulting in large-scale conflicts such as large-scale owner groups engaging in demolition site banner protests and physical conflicts with demolition personnel [32]. Case studies show that the occurrence of large-scale mass incidents is a great blow to the credibility of the government, and the development costs will inevitably increase substantially. More seriously, the project may remain incomplete.

(3) Interest factor $\rightarrow$ Individual owner extremist behavior $\rightarrow$ Large-scale owner groups prevent demolition $\rightarrow$ Difficult urban regeneration.

Government institutions hold public power; public power involves authority, coercion and dominance [33]. In the face of strong public power, any individual owner will appear extremely weak or even insignificant [34]. The rights of relocated householders in urban regeneration are very vulnerable to public power, and it is difficult for them to take effective measures to deal with infringement from public power [31]. More seriously, developers and governments have more common interests in regeneration, and it is easy for them to form interest alliances [35]. Under such circumstances, it is conceivable that the owners are in a completely different position from the government and the developers [36]. Case studies revealed that, in this situation, owners may take some extreme measures such as self-immolation or petitions to maximize their interests. With the popularity of self-media and social networking sites, individual incidents can easily trigger large-scale protests against demolition by owner groups [14]. Many case studies show that large-scale anti-demolition actions are indeed the major reasons for the failure of urban regeneration.

(4) Legal factor $\rightarrow$ Individual owner extremist behavior $\rightarrow$ Large-scale owner groups prevent demolition $\rightarrow$ Difficult urban regeneration.

In urban regeneration, due to the imperfect laws and regulations in China, when the government is driven by self-interest, a lack of fairness and reasonableness in the formulation of compensation and resettlement standards can easily lead to low compensation standards and unreasonable resettlement offerings [37]. The government obtains higher land value-added income through land transfer, and the developer obtains project development income in the view of the owner of the property. When sharing land value-added income, owners who are in a weak position often have difficulty obtaining reasonable benefits [38]. When the owner group is unable to solve these problems through legal means such as litigation, it will engage in excessive acts such as hanging banners at the demolition site and engaging in violence with demolition personnel to express dissatisfaction, which may lead to indefinite delays in project regeneration.

(5) Interest factor $\rightarrow$ Small-scale owner groups prevent demolition $\rightarrow$ Large-scale owner groups collective petition $\rightarrow$ Difficult urban regeneration.

Sustainable urban regeneration should be people-oriented [39]. When the corresponding compensation and resettlement provisions cannot guarantee owners' residences, lives and employment, there will be dissatisfaction among owners [40]. Case studies revealed that when interests are infringed, most property owners will first take actions such as banner protests at the demolition site and physical conflicts with demolition personnel. When these actions are ineffective, owners may take more incisive 
actions, such as large-scale demonstrations and petitions [41]. When relevant government departments do not respond promptly, it is difficult to smoothly carry out the urban regeneration project [42].

(6) Interest factor $\rightarrow$ Small-scale owner groups prevent demolition $\rightarrow$ Large-scale owner group events $\rightarrow$ Difficult urban regeneration.

In terms of land transfer fees, developers cannot bargain with the authoritative government [16]. In order to minimize the cost of land acquisition, developers will try to reduce the resettlement compensation that they must pay to the owners [17]. Case studies revealed that that the owners hope to obtain a considerable compensation for demolition. From this point of view, there is a mutually exclusive relationship between developers and the owners. If owner groups fail to negotiate with the relevant parties, more large-scale mass events will occur as owners express dissatisfaction with the developers and the government, which may reduce the credibility of the government and the brand reputation of the developer [43].

(7) Legal factor $\rightarrow$ Small-scale owner group events $\rightarrow$ Large-scale owner groups prevent demolition $\rightarrow$ Difficult urban regeneration.

Establishing appropriate legal procedures is the basis for the efficient implementation of urban regeneration work [44]. Case studies revealed that standardized regeneration behavior has an important impact on stakeholder conflicts. Difficulty in handling the legal procedures not only increases the time and input cost of the developers, but also can result in the occurrence of illegal situations and behaviors [28]. Although owner groups may refuse to demolition, developers can forcefully demolish houses based on market opportunities, cost savings and relevant laws [35]. This may cause some owner groups to engage in riots and petitions, and when relevant government departments and developers do not respond appropriately, it may trigger large-scale owner groups to prevent demolition, as an important bargaining chip to protect their own interests, forcing the government and developers to meet their needs [34].

\subsection{Discussion}

Judging from the behaviors of major stakeholders in the past urban regeneration projects, the expected difference in project returns can be very large, and the interests of the various stakeholders can be very different. If owners' demands are not met, they can refuse to participate in the regeneration process using the backing of laws and regulations, media power, and even violent resistance [45]. For developers, it is impossible to compensate completely at market prices [46]. Developers must implement uniform compensation standards while safeguarding their own interests; they cannot change standards at different stages of the process [47]. Although the government has introduced measures such as real estate appraisal into the project demolition process, it is still difficult to meet the expectations of owners' self-interests. Further, these real estate appraisals provide an excuse for developers to negotiate with the government and revize planning indicators such as the floor area ratio, which can have a critical effect on project planning [48]. At the same time, relevant legal control, information support, market cultivation and other policy tools from the planning approval and implementation management process [49]. This also has important implications for the determination of complex tenure in urban regeneration planning, the assignment of land agreements, and the determination of the proportion of public goods. Unilateral reliance on the government or the market to cope with the distribution of land value-added income during the urban regeneration process is difficult to effectively implement [16]. The sustainability of the regeneration still requires further cooperation between the government, developers and the owners.

Based on the above analysis, we believe that the sustainability of urban regeneration should be reflected in the following aspects: people-oriented humanistic care [15], focusing on social equity [27] and integration of stakeholder goals [22]. Our findings also highlight that the key to sustainable urban regeneration lies in how conflicts caused by interest factors are resolved. Therefore, by incorporating new mechanisms such as interest coordination, regeneration incentives and public participation into existing urban regeneration governance, we propose an alternative Social-Based Solution (SBS). 
As shown in Figure 5, this solution integrates the demands of the government, developers and property owners, and achieves a partnership among the three stakeholders to enhance the sustainability of urban regeneration [50]. This SBS comprises two aspects: Internal coordination mechanisms and external guarantee mechanisms. Internal coordination measures include expression mechanisms, constraint mechanisms, compensation mechanisms and integration mechanisms. External safeguard measures emphasize the important role of social media, Non-governmental organizations (NGOs) and other influential social forces in the coordination of the interests of various stakeholders in urban regeneration.

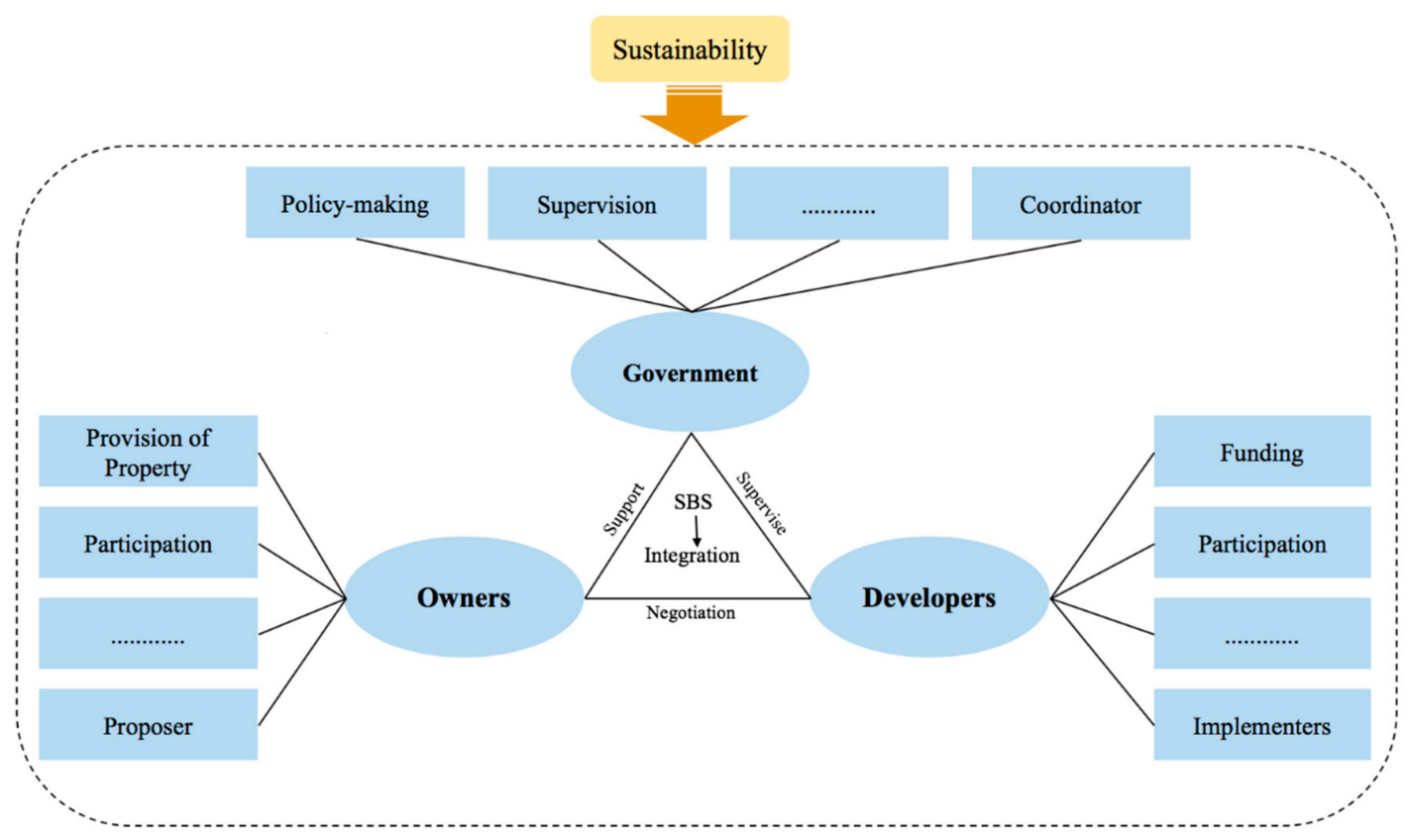

Figure 5. The Sustainability of urban regeneration.

In sustainable urban regeneration, it is necessary to form a new understanding based on the property rights system; one that is guided by market law and characterized by a balance of interests [35]. In practice, sustainable urban regeneration emphasizes that government-led practice, public participation and market operation go hand in hand. The owner and the developer need to negotiate the distribution of interests and support the relevant decision-making of government departments [30]. In particular, public participation should be greatly enhanced and should be a key factor in judging the feasibility and rationality of the regeneration path; this would encourage government decision-making to fully take into account the demands of multiple stakeholders [50]. Stakeholders should also define their own position in this sustainability system. For example, the government is the decision-maker [10], supervisor [14] and coordinator [18]; the owner is the property provider [21], participant [29] and adviser [5]; the developer is the fund provider [31], participant [20] and implementer [6].

\section{Conclusions and Policy Implication}

For decades, frequent conflicts among stakeholders have presented significant problems for urban regeneration in China. Conflicts have brought about many adverse effects for stakeholders, including economic losses and mass incidents. Much of the trust that provides stakeholder cohesion has disappeared. To ensure the success of large-scale urban regeneration campaigns, it is critical to analyse how stakeholder conflicts are conducted in order to identify the critical factors that influence conflicts. Based on such findings, we can provide an SBS that better promotes stakeholder cooperation and prevents or reduces unnecessary conflicts. 
This paper investigated the path of stakeholder conflict conduction in urban regeneration. The findings can be summarized as follows: different conflict factors can lead to conflict events; if the conflict events are not controlled, there are post-conflict outcomes, including difficult urban regeneration. 33 conflict factors were identified through literature review and case studies. These factors were divided into 5 indicators: Interest, legal, society, implementation and management. Compared with previous studies, the conduction pathways in this study not only consider the intrinsic characteristics of a single factor, but also consider the internal relationships between factors. Therefore, our pathway analysis is more systematic than previous studies of stakeholder conflict in urban regeneration.

SEM was used to examine pathways between the 33 different factors; 35 conflict conduction paths were identified. According to Pareto's law, the 35 conflict conduction paths were arranged in order of strength of coefficient, from largest to smallest. The top 7 pathways were chosen as the critical paths. The overall coefficient for the 7 critical conduction paths was 2.1901 , accounting for $39.168 \%$ of the total variance. That is, nearly $40 \%$ of the post-conflict outcomes of stakeholder conflicts in urban regeneration were caused by the 7 critical paths. In addition, 5 of the 7 critical paths were formed by factors of interest; the conductivity coefficients for these pathways were 0.3641 , $0.3555,0.3503,0.2968$ and 0.2715 , respectively. The results revealed that an initial conflict of interest is conducted and spread by the conduction carrier and is gradually enlarged under the influence of internal and external conflict factors in the urban regeneration system. Based on the findings, to ensure the sustainability of urban regeneration, government decision makers should adopt advanced SBS technologies, for example, regional cooperative planning and public participation. Cooperation and win-win is the goal of stakeholder conflict resolution in urban regeneration. Based on the principles of integrity and cooperation, an SBS was constructed comprising two aspects: Internal coordination mechanism and external guarantee mechanism. Internal coordination measures include expression mechanisms, constraint mechanisms, compensation mechanism and integration mechanisms. External safeguard measures emphasize the important role of social media, NGOs and other influential social forces in the coordination of interests of various stakeholders in urban regeneration.

Stakeholders involved in urban regeneration should engage in an inclusive partnership, not a zero-sum relationship with one winner and one loser; all stakeholders should strive for a win-win situation. Taking into account the various interest of stakeholders, and with the aim of sustainable urban regeneration, we propose a new urban regeneration cooperation conceptual framework for stakeholder integration, and hope to provide an SBS for promoting the successful implementation of urban regeneration in China. However, it should be noted that although the conflict path coefficients for legal, management and other factors were not as important as those for interest factors, they should still be considered critical aspect of conflict resolution. Respondents' low evaluation of these other factors may simply mean that conflicts caused by interest factors are more acute, while these other factors have not attracted due attention from decision makers, developers and owners of the many ongoing urban regeneration projects in China.

Author Contributions: Conceptualization, Y.W.; methodology, Y.W.; formal analysis, Y.W. and P.X.; data curation, Y.W.; writing—original draft preparation, Y.W.; visualization, Y.W.; supervision, P.X.; funding acquisition, P.X.

Funding: This study was supported by a joint grant from Project No. 2017CDJSK03XK19, 2018CDXYJG0047 supported by the Fundamental Research Funds for the Central Universities, and Project No. 2018ZD02 supported by the Social Science Planning Projects in Chongqing, China.

Conflicts of Interest: The authors declare no conflict of interest.

\section{References}

1. Peng, Y.; Lai, Y.; Li, X.; Zhang, X. An alternative model for measuring the sustainability of urban regeneration: The way forward. J. Clean. Prod. 2015, 109, 76-83. [CrossRef]

2. Zhong, S. Artists and Shanghai's culture-led urban regeneration. Cities 2016, 56, 165-171. [CrossRef] 
3. Wang, Y.; Xiang, P. Urban sprawl sustainability of mountainous cities in the context of climate change adaptability using a coupled coordination model: A case study of Chongqing, China. Sustainability 2019, 11, 20. [CrossRef]

4. Liu, F.; Zhang, Y. An analysis of Shenzhen urban renewal system based on the perspective of property rights reconstruction and benefit sharing. Urban Develop. Res. 2015, 2, 25-30.

5. $\mathrm{Ng}, \mathrm{M}$. Governing green urbanism: The case of Shenzhen, China. J. Urban Affairs 2019, 41, 64-82. [CrossRef]

6. Xu, K.; Shen, G.; Liu, G.; Martek, I. Demolition of existing buildings in urban renewal projects: A decision support system in the China context. Sustainability 2019, 11, 491. [CrossRef]

7. Ge, F. Shanghai's simultaneous purchase and rent housing system meets the key point of supply-side reform. China Econ. Wkly. 2017, 28, 3-5.

8. Chongqing Statistics. Available online: www.cqtj.gov.cn (accessed on 16 August 2019).

9. Liu, Y.; Zhu, A.X.; Wang, J.; Li, W.; Hu, G.; Hu, Y. Land-use decision support in brownfield redevelopment for urban renewal based on crowdsourced data and a presence-and-background learning (PBL) method. Land Use Policy 2019, 88, 104188. [CrossRef]

10. Jung, T.H.; Lee, J.; Yap, M.H.; Ineson, E.M. The role of stakeholder collaboration in culture-led urban regeneration: A case study of the Gwangju project, Korea. Cities 2015, 44, 29-39. [CrossRef]

11. Institute of Sociology, Chinese Academy of Social Sciences. Social Blue Paper: Analysis and Prediction of China's Social Situation; Social Sciences Academic Press: Beijing, China, 2019.

12. Tan, X.; Altrock, U. Struggling for an adaptive strategy? Discourse analysis of urban regeneration processes-A case study of Enning Road in Guangzhou City. Habitat Int. 2016, 56, 245-257. [CrossRef]

13. Guo, X.; Chen, Y.; Xu, S.; Tian, L. Research on interest compensation mechanism of removal households in the process of urban renewal: Based on the perspective of removal in Wuhan. Urban Geog. 2017, 22, 6-7.

14. Xi, Y. Public participation in urban renewal research based on stakeholder analysis. J. Hous. Real Estate 2018, $509,129$.

15. Agbiboa, D. Conflict analysis in 'world class' cities: Urban renewal, informal transport workers, and legal disputes in Lagos. Urban Forum 2017, 2, 1-18. [CrossRef]

16. Yang, J.; Xu, C. Breakthrough and limitation of marketization of urban renewal: From the perspective of transaction cost. Urban Plan. 2016, 9, 32-38.

17. Peng, K. The renewal model of governing cities in china from the perspective of new marxism: reconstruction of the role of space stakeholders and partnership. Planner 2018, 34, 17-25.

18. Lees, L. The urban injustices of new labour's "new urban renewal": The case of the Aylesbury Estate in London. Antipode 2014, 46, 921-947. [CrossRef]

19. Wang, Y.; Li, J.; Zhang, G.; Li, Y.; Asare, M.H. Fuzzy evaluation of comprehensive benefit in urban renewal based on the perspective of core stakeholders. Habitat Int. 2017, 66, 163-170. [CrossRef]

20. Yu, T.; Liang, X.; Shen, G.Q.; Shi, Q.; Wang, G. An optimization model for managing stakeholder conflicts in urban redevelopment projects in China. J. Clean. Prod. 2019, 212, 537-547. [CrossRef]

21. Ruming, K. Post-political planning and community opposition: Asserting and challenging consensus in planning urban regeneration in Newcastle, NSW. Geogr. Res. 2017, 56, 58-69.

22. Lian, H.; Zhang, Y.; Zeng, Y. Conflict and resolution of land expropriation from the perspective of institutional adaptation theory: A case study of land expropriation and removal at Beijing New Airport. Chin. Public Admin. 2017, 12, 119-124.

23. Shao, M. Compensation for demolition and relocation in the process of urbanization in china: Conflict and improvement: A game method framework based on the psychological endowment effect of commercial expropriation and demolition. J. Econ. Sys. Ref. 2015, 6, 5-11.

24. Yu, T.; Shen, G.Q.; Shi, Q.; Lai, X.; Li, C.Z.; Xu, K. Managing social risks at the housing demolition stage of urban redevelopment projects: A stakeholder-oriented study using social network analysis. Int. J. Proj. Manag. 2017, 35, 925-941. [CrossRef]

25. Rădulescu, C.; Ştefan, O.; Rădulescu, G.; Rădulescu, A.; Rădulescu, M. Management of stakeholders in urban regeneration projects. Case study: Baia-Mare, Transylvania. Sustainability 2016, 8, 238. [CrossRef]

26. Liwei, D.; Siyuan, Y. Protection and renewal of historic blocks based on the theory of self-organization: A case study of Si Street and Xinanying in Nantong City. J. Landscape Res. 2018, 10, 127-134.

27. Tao, Z.; Qi, C. Research on the influencing factors of public attitude to neighborhood avoidance problem based on structural equation model. Urban Develop. Res. 2018, 25, 106-113. 
28. Zhao, X.; Zhao, G.; Zhang, H.; Zhang, L.; Hu, Z.; Liu, X. Analysis of the application of Pareto's law and PDCA principle in the teaching of ICU nursing. Chin. J. Pract. Nurs. 2018, 34, 1159-1162.

29. Liu, B.; Wang, X.; Xia, N.; Ni, W. Critical success factors for the management of public participation in urban renewal projects: perspectives from governments and the public in China. J. Urban Plan. Dev. 2018, 144, 04018026. [CrossRef]

30. Huston, S.; Rahimzad, R.; Parsa, A. 'Smart'sustainable urban regeneration: Institutions, quality and financial innovation. Cities 2015, 48, 66-75. [CrossRef]

31. Wang, X.; Yang, H.; Shi, M.; Zhou, D.; Zhang, Z. Managing stakeholders' conflicts for water reallocation from agriculture to industry in the Heihe River Basin in Northwest China. Sci. Total Environ. 2015, 505, 823-832. [CrossRef]

32. Tao, X. A study on the transformation strategy of urban old area reform mode in China: From "economic old area reform" to "social urban renewal". Urban Develop. Res. 2015, 22, 111-116.

33. Tavella, E.; Lami, I. Negotiating perspectives and values through soft or in the context of urban renewal. J. Oper. Res. Soc. 2019, 70, 136-161. [CrossRef]

34. Chiu, Y.; Lee, M.; Wang, J. Culture-led urban regeneration strategy: an evaluation of the management strategies and performance of urban regeneration stations in Taipei City. Habitat Int. 2019, 86, 1-9. [CrossRef]

35. Wang, X.; Shen, S. From "three old reconstruction" to urban renewal: Reflections on the Establishment of Urban Renewal Bureau in Guangzhou. J. Urban Plan. 2015, 3, $22-27$.

36. Sun, S.; Zhou, Y. Study on renewal mechanism of tianzifang district in shanghai. J. Urban Plan. 2015, 1, 39-45.

37. Xie, D.; Zhou, X. Social conflict, interest game and renewal of historic blocks: A case study of Enning Road, Guangzhou. Urban Develop. Res. 2014, 21, 86-92.

38. Lai, Y.; Tang, B. Institutional barriers to redevelopment of urban villages in China: A transaction cost perspective. Land Use Policy 2016, 58, 482-490. [CrossRef]

39. Gilderbloom, J. Ten Commandments of urban regeneration: creating healthy, safe, affordable, sustainable, and just neighbourhoods. Local Environ. 2016, 21, 653-660. [CrossRef]

40. Forouhar, A.; Hasankhani, M. Urban regeneration mega projects and residents' quality of life: Evidence from historical religious center of Mashhad Metropolis. J. Urban Health Bull. N. Y. Acad. Med. 2018, 95, 1-13.

41. Davies, S. Partnerships and Regimes: The Politics of Urban Regeneration in the UK; Routledge: London, UK, 2017.

42. Guy, S.; Henneberry, J.; Rowley, S. Development cultures and urban regeneration. Urban Stud. 2014, 39, 1181-1196. [CrossRef]

43. Couch, C. City of Change and Challenge: Urban Planning and Regeneration in Liverpool; Routledge: London, UK, 2017.

44. Yildiz, S.; Kivrak, S.; Arslan, G. Factors affecting environmental sustainability of urban regeneration projects. Civ. Eng. Environ. Sys. 2018, 34, 1-14.

45. Egan, M.; Lawson, L.; Kearns, A.; Conway, E.; Neary, J. Neighbourhood demolition, relocation and health. A qualitative longitudinal study of housing-led urban regeneration in Glasgow, UK. Health Place 2015, 33, 101-108. [CrossRef] [PubMed]

46. McCarthy, J. Partnership, Collaborative Planning and Urban Regeneration; Routledge: London, UK, 2016.

47. La Rosa, D.; Privitera, R.; Barbarossa, L.; La Greca, P. Assessing spatial benefits of urban regeneration programs in a highly vulnerable urban context: A case study in Catania, Italy. Landscape Urban Plan. 2017, 157, 180-192. [CrossRef]

48. Campbell, P.; Cox, T.; O'Brien, D. The social life of measurement: How methods have shaped the idea of culture in urban regeneration. J. Cult. Econ. 2017, 10, 49-62. [CrossRef]

49. Tang, W. Creative industries, public engagement and urban redevelopment in Hong Kong: Cultural regeneration as another dose of isotopia? Cities 2016, 56, 156-164. [CrossRef]

50. Ferilli, G.; Sacco, P.; Blessi, G. Beyond the rhetoric of participation: New challenges and prospects for inclusive urban regeneration. City Cult. Soc. 2016, 7, 95-100. [CrossRef]

(C) 2019 by the authors. Licensee MDPI, Basel, Switzerland. This article is an open access article distributed under the terms and conditions of the Creative Commons Attribution (CC BY) license (http://creativecommons.org/licenses/by/4.0/). 